\title{
INTRAVENOUS LABETALOL VERSUS ORAL NIFEDIPINE FOR ACUTE BLOOD PRESSURE CONTROL IN SEVERE PREGNANCY-INDUCED HYPERTENSION- A RANDOMISED TRIAL
}

Ramprasad Dey¹, Arunima Mukhopadhyay², Subhash Chandra Biswas³, Siuli Chanda Chakrabarti4, Joyeeta Monda ${ }^{5}$, Swarnalata Soren ${ }^{6}$

${ }^{1}$ Associate Professor, Department of Obstetrics and Gynaecology, Chittaranjan Seva Sadan College of Obstetrics, Gynaecology \& Child

Health, Kolkata.

${ }^{2}$ Associate Professor, Department of Surgery, Calcutta National Medical College, Kolkata.

3 Professor, Department of Obstetrics and Gynaecology, IPGMER, Kolkata.

${ }^{4}$ Associate Professor, Department of Obstetrics and Gynaecology, Chittaranjan Seva Sadan College of Obstetrics, Gynaecology \& Child

Health, Kolkata.

${ }^{5}$ RMO Cum Clinical Tutor, Department of Obstetrics and Gynaecology, Chittaranjan Seva Sadan College of Obstetrics, Gynaecology \&

Child Health, Kolkata.

${ }^{6}$ Assistant Professor, Department of Obstetrics and Gynaecology, Chittaranjan Seva Sadan College of Obstetrics, Gynaecology \& Child Health, Kolkata.

\begin{tabular}{l}
\hline ABSTRACT \\
BACKGROUND \\
Hypertensive disorders of pregnancy complicate approximately $12 \%$ to $22 \%$ of all pregnancies. Various complications occur due to \\
hypertensive disorder. Although delivery of the foetus is the definitive treatment yet then there are many drugs available to control \\
the maternal blood pressure. \\
Aim \& Objectives- To compare efficacy of intravenous labetalol and oral nifedipine when used rapidly to lower high blood pressure \\
in severe pregnancy-induced hypertension.
\end{tabular}

\section{MATERIALS AND METHODS}

It is a hospital-based, prospective, interventional, randomised control trial conducted at Chittaranjan Seva Sadan from April 2014 to March 2016. 150 pregnant women in between 34-41 weeks gestation with BP $\geq 160 / 110$ were recruited for the study. They were randomly allocated into two groups. In group A, intravenous labetalol $20 \mathrm{mg}$ was given and drug was repeated at $20 \mathrm{minutes}$ interval in an escalating dose regimen of $40,80,80$ and $80 \mathrm{mg}$ to achieve the target blood pressure $(\mathrm{BP}<150 / 90)$. In group $\mathrm{B}$, nifedipine $10 \mathrm{mg}$ was given orally, 20 minutes interval up to a maximum of 5 doses. Maternal parameters studied are amount of drug, time required, crossover treatment, any complication \& mode of delivery. Results were analysed with the Student's t-test and Mann-Whitney U test.

\section{RESULTS}

Most patients belonged to 38-40 weeks gestational age, $80 \%$ in the labetalol group \& $84 \%$ in the nifedipine group. Mean SBP was $180 \pm 16 \mathrm{~mm}$ of $\mathrm{Hg}$ in group A and $170 \pm 14 \mathrm{~mm}$ of $\mathrm{Hg}$ in group B (P=0.669). Mean DBP was $116 \pm 8 \mathrm{~mm}$ of $\mathrm{Hg}$ in group A and $110 \pm$ $8 \mathrm{~mm}$ of $\mathrm{Hg}$ in group $\mathrm{B}(\mathrm{P}=0.745)$. The mean dosage of drug required was $94 \pm 35.8 \mathrm{mg}$ in group A and $20.8 \pm 10.9 \mathrm{mg}$ in group $\mathrm{B}$ $(\mathrm{P}<0.001)$. The mean time required was $45.2 \pm 11.5$ minutes in group $A$ and $43.6 \pm 12.5$ minutes in group $B(P=0.511)$. Most of the patients were controlled by two doses of each drug, $56 \%$ in the labetalol group and $61.33 \%$ in the nifedipine group.

\section{CONCLUSION}

Intravenous labetalol and oral nifedipine are almost equally effective and well tolerated in acute blood pressure control in severe pregnancy-induced hypertension. However, labetalol seems to be safer, with quicker control of blood pressure with fewer side effects.

\section{KEYWORDS}

Labetalol, Nifedipine, Hypertension, Pregnancy.

HOW TO CITE THIS ARTICLE: Dey R, Mukhopadhyay A, Biswas SC, et al. Intravenous labetalol versus oral nifedipine for acute blood pressure control in severe pregnancy-induced hypertension- A randomised trial. J. Evolution Med. Dent. Sci. 2017;6(92): 6578-6582, DOI: $10.14260 /$ jemds/2017/1426

\section{BACKGROUND}

Hypertensive disorders of pregnancy complicate approximately $12 \%$ to $22 \%$ of all pregnancies and are directly responsible for $17.6 \%$ of maternal deaths in the United States.1,2

'Financial or Other Competing Interest': None.

Submission 19-10-2017, Peer Review 15-11-2017,

Acceptance 21-11-2017, Published 04-12-2017.

Corresponding Author:

Dr. Ramprasad Dey,

\#836 Block-P, New Alipore, Kolkata-700053.

E-mail: drrpdey@gmail.com

DOI: $10.14260 / \mathrm{jemds} / 2017 / 1426$

(c) (i)
Gestational hypertension, which includes preeclampsia and eclampsia, is responsible for $70 \%$ of cases, whereas chronic hypertension represents $30 \%$ of hypertensive disorders in pregnancy. ${ }^{3}$

Severe Pregnancy-induced hypertension $(\mathrm{PIH})$ is a disorder in pregnancy which is characterised by a systolic blood pressure of $\geq 160 \mathrm{~mm}$ of $\mathrm{Hg}$ and a diastolic blood pressure of $\geq 110 \mathrm{~mm}$ of $\mathrm{Hg}$. Severe Pre-eclampsia is characterised by severe PIH superimposed with proteinuria $>300 \mathrm{mg} / 24$ hrs. urine. ${ }^{4,5}$

Various complications occur due to hypertensive disorder. When mean arterial pressure exceeds $140 \mathrm{~mm}$ of $\mathrm{Hg}$ (equivalent to 180/120) there is a significant risk of 
maternal cerebral vascular damage. Therefore, it is recommended that $\mathrm{BP} \geq 160 / 110 \mathrm{~mm}$ of $\mathrm{Hg}$ with or without proteinuria $(>300 \mathrm{mg} / 24 \mathrm{hrs}$. urine) must be treated as hypertensive urgency. ${ }^{6}$

Although delivery of the foetus is the definitive treatment, there are many drugs available to control the maternal blood pressure. Recent guidance from the National Institute for Health and Clinical Excellence, UK, recommends inpatient treatment of severe hypertension of pregnancy with labetalol (oral or intravenous), intravenous hydralazine or oral nifedipine as first-line alternative antihypertensives within the critical care setting. ${ }^{7}$

Of these drugs, labetalol and nifedipine are commonly used in our hospital setup. Nifedipine is most commonly used for treatment of hypertension during pregnancy based on its effectiveness and safety for both mother and foetus, but it takes longer time to act. Care must be taken when nifedipine is administered to patients who are receiving concomitant magnesium sulphate because an exaggerated hypotensive response may occur. ${ }^{8}$ Nifedipine appears to be safe for the treatment of hypertensive crisis in pregnancy.

Labetalol is a combined $\alpha$ - and $\beta$-adrenoreceptor antagonist that may be used to induce a controlled rapid decrease in blood pressure through decreased systemic vascular resistance in patients with severe hypertension. Reports on the efficacy and safety of labetalol in the treatment of hypertension during pregnancy are favourable. ${ }^{9,10,11}$ The advantage of labetalol is, it is available as both injectable and oral preparations, and time of onset of action is earlier when compared to nifedipine.

So the present study was carried out to find the effective antihypertensive agent out of the two studied drugs in regard to dose and time for acute high blood pressure control in severe pregnancy-induced hypertension.

\section{MATERIALS AND METHODS}

The study has been carried out in the Department of Obstetrics and Gynaecology, Chittaranjan Seva Sadan College of Obstetrics, Gynaecology and Child Health, Kolkata from April 2014 to March 2016. It was a hospital based prospective randomised interventional comparative trial. The study was approved by ethics committee of the institution and the written informed consent was taken from all women. In our study, we have chosen 150 mothers in between 34 to 41 weeks of gestation with a BP of $\geq 160 / 110$., Convenience sampling technique was followed due to fixed duration of study. Thus, sample size estimation was also done at conveniences. Patients complicated with eclampsia, any organ failure, post-partum women, known hypertensiveessential or secondary were excluded from the study.

They were randomly allocated by computer generated number into two Groups (Group A \& Group B). In Group A, intravenous labetalol $20 \mathrm{mg}$ was given and drug was repeated at 20 mints interval in an escalating dose regimen of $40,80,80$ and $80 \mathrm{mg}$ up to a maximum of $300 \mathrm{mg}$ to achieve the target blood pressure. 6 In Group B, Nifedipine $10 \mathrm{mg}$ was given orally, $20 \mathrm{~min}$ interval up to a maximum of 5 doses i.e. 50mg.6

The target BP was $150 / 90 \mathrm{~mm}$ of $\mathrm{Hg}$ and at this point study regimen was stopped. After the successful control of BP further antihypertensive was given orally as chosen by provider. The time interval and dosage of drugs required to reach the target $\mathrm{BP}$ by the two drugs were noted separately. Adverse effects of the drugs if any were detected carefully and treated accordingly. It was also noted if any additional drugs or crossover of drug were required if the BP was not controlled with study regimen.

Finally, data obtained were statistically analysed with suitable statistical software. Normally distributed continuous data were analysed with the Student's t-test and nonnormally distributed with Mann-Whitney U test. Categorical variance was analysed with Fisher's exact test. All tests were two sided and $\mathrm{P}<0.05$ were taken as the level of significance.

\section{RESULTS}

We randomised patients (75 in each group) to receive intravenous labetalol injection (in an escalating dose regimen of 20,40, 80, 80 and $80 \mathrm{mg}$ ) in Group A or nifedipine (10 mg tablet, orally, up to five doses) in Group B, every 20 minutes interval until the target blood pressure of $\leq 150 / 90 \mathrm{mmHg}$ was achieved.

All the patients were aged between 20-35 yrs. In the labetalol group, $48 \%$ of the patients were between $25-30$ years $\&$ in the nifedipine group, $42 \%$ of all the patients were between 25-30 years. Maximum patients were primigravidae in both the groups, $58 \%$ in the labetalol group \& $50 \%$ in the nifedipine group. Mean Gestational age in both groups was 38-40 weeks, $80 \%$ in the labetalol Group \& $84 \%$ in the nifedipine group (Table -1).

Most of the patients had a systolic BP of 160-180 mm of $\mathrm{Hg}, 52 \%$ and $48 \%$ in the labetalol and nifedipine group respectively (Table-2). Mean SBP was $180 \pm 16 \mathrm{~mm}$ of $\mathrm{Hg}$ in group $\mathrm{A}$ and $170 \pm 14 \mathrm{~mm}$ of $\mathrm{Hg}$ in group $\mathrm{B}(\mathrm{P}=0.669)$.

Most of the patients had a diastolic BP of 110-130 mm of $\mathrm{Hg}$; $84 \%$ and $78.66 \%$ in the labetalol and nifedipine Group respectively (Table-3). Mean DBP was $116 \pm 8 \mathrm{~mm}$ of $\mathrm{Hg}$ in Group A and $110 \pm 8 \mathrm{~mm}$ of Hg in Group B (P=0.745).

Most of the patients were controlled by two doses of each drug, 56\% in the labetalol group and $61.33 \%$ in the nifedipine group. $12 \%$ and $13.33 \%$ in the labetalol and nifedipine group respectively were not controlled even by 5 doses of either drug and required crossover drug therapy (Table-4).

Most of the patients were controlled within 40 minutes of each drug, $56 \%$ in the labetalol group and $61.33 \%$ in the nifedipine group (Table-5). The mean time required was 45.2 \pm 11.5 minutes in group $\mathrm{A}$ and $43.6 \pm 12.5$ minutes in group $\mathrm{B}$ $(\mathrm{P}=0.511)$.

Most of the patients were controlled with two doses of each drug i.e. $56 \%$ patients in the labetalol group required 60 $\mathrm{mg}$ of the drug and $61.33 \%$ patients in the nifedipine group required $20 \mathrm{mg}$ of the drug (Table 6). The mean dosage of drug required was $94 \pm 35.8 \mathrm{mg}$ in group $\mathrm{A}$ and $20.8 \pm 10.9$ mg in group $\mathrm{B}(\mathrm{P}<0.001)$.

Only $12 \%$ and $13.33 \%$ in the labetalol and nifedipine group respectively were not controlled even by 5 doses of either drug and required crossover drug therapy (Table-7).

Table 8 shows the comparison of adverse effects of the drugs. $4 \%$ patients had headache in the labetalol group. In the nifedipine group, $4 \%$ of the patients had postural hypotension and $4 \%$ of them had drowsiness. There was no significant difference in mode of delivery \& perinatal outcome between two groups. 


\begin{tabular}{|c|c|c|c|c|c|}
\hline \multirow{2}{*}{$\begin{array}{c}\text { Gestational Age } \\
\text { (weeks) }\end{array}$} & \multicolumn{2}{|c|}{ Labetalol } & \multicolumn{2}{|c|}{ Nifedipine } & \multirow{6}{*}{$\begin{array}{c}p= \\
0.3257\end{array}$} \\
\hline & No. & $\%$ & No. & $\%$ & \\
\hline $36-37$ & 10 & 13.33 & 9 & 12 & \\
\hline $38-40$ & 60 & 80 & 63 & 84 & \\
\hline$>40$ & 5 & 6.66 & 3 & 4 & \\
\hline Total & 75 & 100 & 75 & 100 & \\
\hline Table 1. Co & $\begin{array}{c}\text { aris } \\
\text { of }\end{array}$ & $\begin{array}{l}\text { fGes } \\
\text { wo G }\end{array}$ & $\begin{array}{l}\text { onal } \\
\text { ps }\end{array}$ & & \\
\hline
\end{tabular}

Most patients with PIH belonged to 38-40 weeks gestational age, $80 \%$ in the labetalol group \& $84 \%$ in the nifedipine group.

\begin{tabular}{|c|c|c|c|c|c|}
\hline \multirow{2}{*}{$\begin{array}{l}\text { Systolic BP } \\
\text { (mm of Hg) }\end{array}$} & \multicolumn{2}{|c|}{ Labetalol } & \multicolumn{2}{|c|}{ Nifedipine } & \multirow{6}{*}{$p=0.669$} \\
\hline & No. & $\%$ & No. & $\%$ & \\
\hline $160-180$ & 39 & 52 & 36 & 48 & \\
\hline $180-200$ & 21 & 28 & 27 & 36 & \\
\hline$>200$ & 15 & 20 & 12 & 16 & \\
\hline Total & 75 & 100 & 75 & 100 & \\
\hline
\end{tabular}

Most of the patients had a systolic BP of $160-180 \mathrm{~mm}$ of $\mathrm{Hg}, 52 \%$ and $48 \%$ in the labetalol and nifedipine group respectively.

\begin{tabular}{|c|c|c|c|c|c|}
\hline \multirow{2}{*}{$\begin{array}{c}\text { Diastolic BP } \\
\text { (mm of Hg) }\end{array}$} & \multicolumn{2}{|c|}{ Labetalol } & \multicolumn{2}{c|}{ Nifedipine } & \\
\cline { 2 - 5 } & No. & $\mathbf{\%}$ & No. & $\mathbf{\%}$ & \multirow{2}{*}{} \\
\hline $110-130$ & 63 & 84 & 59 & 78.66 & \multirow{2}{*}{$=0.745$} \\
\hline$>130$ & 12 & 16 & 16 & 21.33 & \\
\hline Total & $\mathbf{7 5}$ & $\mathbf{1 0 0}$ & $\mathbf{7 5}$ & $\mathbf{1 0 0}$ & \\
\hline
\end{tabular}

Most of the patients had a diastolic BP of 110-130 mm of $\mathrm{Hg} 84 \%$ and $78.66 \%$ in the labetalol and nifedipine group respectively.

\begin{tabular}{|c|c|c|c|c|}
\hline \multirow{2}{*}{$\begin{array}{c}\text { No. of } \\
\text { Doses }\end{array}$} & \multicolumn{2}{|c|}{ Labetalol } & \multicolumn{2}{c|}{ Nifedipine } \\
\cline { 2 - 5 } & No. & $\mathbf{\%}$ & No. & $\mathbf{\%}$ \\
\hline 1 & 13 & 17.33 & 15 & 20 \\
\hline 2 & 42 & 56 & 46 & 61.33 \\
\hline 3 & 8 & 10.66 & 2 & 2.66 \\
\hline 4 & 3 & 4 & 2 & 2.66 \\
\hline 5 & 9 & 12 & 10 & 13.33 \\
\hline Total & $\mathbf{7 5}$ & $\mathbf{1 0 0}$ & $\mathbf{7 5}$ & $\mathbf{1 0 0}$ \\
\hline Table 4. Comparison of No. of Doses of Drugs Required to \\
Control BP between Two Groups \\
\hline
\end{tabular}

Most of the patients were controlled by two doses of each drug $56 \%$ in the labetalol group and $61.33 \%$ in the nifedipine group. $12 \%$ and $13.33 \%$ in the labetalol and nifedipine group respectively were not controlled by 5 doses of either drug and required crossover drug therapy.

\begin{tabular}{|c|c|c|c|c|c|}
\hline \multirow{2}{*}{$\begin{array}{c}\text { TIME } \\
\text { (in Minutes) }\end{array}$} & \multicolumn{2}{|c|}{ Labetalol } & \multicolumn{2}{|c|}{ Nifedipine } & \multirow{8}{*}{$\mathrm{p}=0.511$} \\
\hline & No. & $\%$ & No. & $\%$ & \\
\hline 20 & 13 & 17.33 & 15 & 20 & \\
\hline 40 & 42 & 56 & 46 & 61.33 & \\
\hline 60 & 8 & 10.66 & 2 & 2.66 & \\
\hline 80 & 3 & 4 & 2 & 2.66 & \\
\hline 100 & 9 & 12 & 10 & 13.33 & \\
\hline Total & 75 & 100 & 75 & 100 & \\
\hline \multicolumn{6}{|c|}{$\begin{array}{c}\text { Table 5. Comparison of Time Required to Control } \\
\text { BP of the Two Groups }\end{array}$} \\
\hline
\end{tabular}

Most of the patients were controlled within 40 minutes of each drug $56 \%$ in the labetalol group and $61.33 \%$ in the nifedipine group.

\begin{tabular}{|c|c|c|c|c|c|c|}
\hline \multicolumn{3}{|c|}{ Labetalol } & \multicolumn{3}{|c|}{ Nifedipine } & \multirow{8}{*}{$\mathrm{p}=0.511$} \\
\hline $\begin{array}{c}\text { Amount } \\
\text { of Drug } \\
\text { (mg) }\end{array}$ & No. & $\%$ & $\begin{array}{c}\text { Amount } \\
\text { of } \\
\text { Drug } \\
\text { (mg) }\end{array}$ & No. & $\%$ & \\
\hline 20 & 13 & 17.33 & 10 & 15 & 20 & \\
\hline 60 & 42 & 56 & 20 & 46 & 61.33 & \\
\hline 140 & 8 & 10.66 & 30 & 2 & 2.66 & \\
\hline 220 & 3 & 4 & 40 & 2 & 2.66 & \\
\hline 300 & 9 & 12 & 50 & 10 & 13.33 & \\
\hline Total & 75 & 100 & TOTAL & 75 & 100 & \\
\hline
\end{tabular}

Most of the patients were controlled with two doses of each drug i.e. $56 \%$ patients in the labetalol group required 60 $\mathrm{mg}$ of the drug and $61.33 \%$ patients in the nifedipine group required $20 \mathrm{mg}$ of the drug.

\begin{tabular}{|c|c|c|c|c|}
\hline \multirow{2}{*}{} & \multicolumn{2}{|c|}{ Labetalol } & \multicolumn{2}{c|}{ Nifedipine } \\
\cline { 2 - 5 } & No. & $\mathbf{\%}$ & No. & $\%$ \\
\hline Required & 9 & 12 & 10 & 13.33 \\
\hline Not required & 66 & 88 & 65 & 86.66 \\
\hline Total & $\mathbf{7 5}$ & $\mathbf{1 0 0}$ & $\mathbf{7 5}$ & $\mathbf{1 0 0}$ \\
\hline Table 7. Patients requiring Crossover Treatment \\
to Control BP between Two Groups \\
\hline
\end{tabular}

The above table shows the no. of patients requiring crossover therapy to control the blood pressure. $12 \%$ and $13.33 \%$ in the labetalol and nifedipine group respectively were not controlled by 5 doses of either drug and required crossover drug therapy.

\begin{tabular}{|c|c|c|}
\hline Adverse Effects & Labetalol & Nifedipine \\
\hline $\begin{array}{c}\text { Postural } \\
\text { Hypotension }\end{array}$ & 0 & 3 \\
\hline Drowsiness & 0 & 3 \\
\hline Headache & 3 & 0 \\
\hline Bradycardia & 0 & 0 \\
\hline Depression & 0 & 0 \\
\hline Nausea & 0 & 0 \\
\hline Hypersensitivity & 0 & 0 \\
\hline Dyspnoea & 0 & 0 \\
\hline \multicolumn{2}{|c|}{ Total } & $\mathbf{3}$ \\
\hline \multicolumn{2}{|c|}{ Table 8. Comparison of the Adverse Effects of } \\
the Two Groups \\
\hline
\end{tabular}

$4 \%$ patients had headache in the labetalol Group. In the nifedipine Group, $4 \%$ of the patients had postural hypotension, $4 \%$ of them had drowsiness.

\section{DISCUSSION}

In the present study, the results indicate that both intravenous labetalol and oral nifedipine are almost equally efficacious having minimal side effects. There was a similar study published in the British Journal of Obstetrics \& Gynaecology in January 2012 by I A Raheem et al ${ }^{6}$ which was a similar double blind randomised trial in the University Hospital in Malaysia with the similar objectives of comparing oral nifedipine with intravenous labetalol in their rapidity to control hypertensive emergencies of pregnancy. 
When the Systolic Blood Pressure was compared between the two groups of the present study, it showed no difference with a $\mathrm{p}$ value of 0.669 . Majority of patients of both groups had a systolic BP of $160-180 \mathrm{~mm}$ of $\mathrm{Hg}(52 \%$ and $48 \%$ in the labetalol and nifedipine group respectively). Mean Systolic Blood Pressure was $186.2 \pm 12 \mathrm{~mm}$ of $\mathrm{Hg}$ in the labetalol group and $175 \pm 12 \mathrm{~mm}$ of $\mathrm{Hg}$ in the nifedipine group. While in the study of IA Raheem et $\mathrm{al}^{6}$ the mean Systolic Blood Pressure was 175 (170-180) $\mathrm{mm}$ of $\mathrm{Hg}$ in nifedipine group and 170 (165-180) $\mathrm{mm}$ of $\mathrm{Hg}$ in labetalol group with a p value of 0.25 .

In the present study when the Diastolic Blood Pressure was compared between the two groups, no difference was seen and the $\mathrm{p}$ value was 0.745 . Most of the patients had a diastolic BP of $110-130 \mathrm{~mm}$ of $\mathrm{Hg}(84 \%$ and $78.66 \%$ in the labetalol and nifedipine group respectively). Mean Diastolic Blood Pressure was $118.11 \pm 8 \mathrm{~mm}$ of $\mathrm{Hg}$ in the labetalol Group and $112 \pm 8 \mathrm{~mm}$ of $\mathrm{Hg}$ in the nifedipine Group. IA Raheem et al ${ }^{6}$ showed that the mean Diastolic Blood Pressure was 110 (110-116) $\mathrm{mm}$ of $\mathrm{Hg}$ in nifedipine group and 108 (100-112) $\mathrm{mm}$ of $\mathrm{Hg}$ in labetalol group with a $\mathrm{p}$ value of 0.012 .

In our present study, most of the patients were controlled within 40 minutes of each drug administration; $56 \%$ in the labetalol group and $61.33 \%$ in the nifedipine group. The mean time required was $47.2 \pm 13.5$ minutes in the labetalol group and $45.6 \pm 14.5$ minutes in the nifedipine group. The comparison showed no difference between the two groups with a $\mathrm{p}$ value of 0.511 . The result of the study done by IA Raheem et al showed that the median time taken to achieve target blood pressure was $30 \mathrm{~min}$. (Interquartile range IQR22.5 to $67.5 \mathrm{~min}$.) versus $45 \mathrm{~min}$. (IQR 30-60 min.) for nifedipine and labetalol, respectively ( $p=0.59)$.

In our present study, most of the patients were controlled by two doses of each drug, 56\% in the labetalol Group and $61.33 \%$ in the nifedipine Group. As per study done by IA Raheem et $\mathrm{al}^{6}$, average number of total antihypertensive doses to achieve Blood Pressure $\leq 150 / 100 \mathrm{~mm}$ of Hg were two (1.5-4.5) in nifedipine group whereas three (2-4) in labetalol group as compared to two for both groups in our study. The present study showed that $12 \%$ and $13.33 \%$ of patients in the labetalol and nifedipine group respectively were not controlled even by 5 doses of either drug and required crossover drug therapy. Whereas in the study of IA Raheem et al, $620 \%$ of patients (i.e. 5 out of 25 patients) in each group required crossover therapy.

Vermillion et al'12 conducted a double-blind trial with the objective of comparing the efficacy of oral nifedipine and intravenous labetalol in acute management of hypertensive emergencies of pregnancy. The result was that the time to achieve the blood pressure goal was significantly shorter with nifedipine (mean \pm SD); $(25 \pm 13.6$ min.) than with labetalol ( $43.6 \pm 25.4 \mathrm{~min}$.) with a p value $=0.002$. None of the patients required crossover therapy. This difference of result can be explained by the difference in their methodology where they used nifedipine in an escalating dose also. Vermillion's drug regimen used escalating oral nifedipine doses $(10 \mathrm{mg}$ initially, then $20 \mathrm{mg}$ for a further four doses, as required; while we had used a flat $10 \mathrm{mg}$ nifedipine dose throughout, and an intravenous labetalol regimen of 20,40, 80,80 and $80 \mathrm{mg}$, as required (identical to our regimen).
As per the Cochrane Review prepared and maintained by The Cochrane Collaboration and published in The Cochrane Library 2013, Issue 7,13 five trials (171 women) were reviewed to compare labetalol with calcium channel blockers (nicardipine and nifedipine). Two trials did not provide outcome data that could be included in an analysis (India 2011; Switzerland 2012). Data provided by fromone trial (50 women) suggested that nifedipine was associated with fewer side-effects for women than labetalol (RR 2.17, 95\% CI 0.98 to 4.79 ) which was borderline for statistical significance. Data is insufficient for reliable conclusions about the comparative effects of these two agents for other outcomes. The Cochrane review $^{13}$ on drugs for the treatment of very high blood pressure in pregnancy thus concluded that until and unless better evidence is available, the choice of antihypertensive should depend on the clinician's experience and familiarity with a particular drug, and its adverse effects. And our study clearly indicates that both intravenous labetalol and oral nifedipine are almost equally efficacious in controlling high Blood Pressure in severe PIH with minimal side effects.

Shekhar et al (2013) ${ }^{\mathbf{1 4}}$ conducted a similar study with labetalol in accelerating dosage and nifedipine in repeated doses every 20 minutes interval up to a maximum of 5 doses. They had enrolled 60 patients from October 2012 to April 2013. The median time taken to achieve target blood pressure was 40 minutes (interquartile range, 20-60 minutes) for nifedipine and 60 minutes (interquartile range 40-85 minutes) for labetalol with a $\mathrm{P}$ value 0.008 . (Compared to mean time required in our study $47.2 \pm 13.5$ minutes in the labetalol group and $45.6 \pm 14.5$ minutes in the nifedipine group). The median dose required was two (interquartile range 1-3) compared with three (interquartile range 2-4.25) for nifedipine and labetalol, respectively $(\mathrm{P}=.008)$ while in our study showed that the average no. of doses required was similar in both the groups i.e. two. No serious adverse maternal or perinatal side effects were noted in either group. They concluded by this trial, that oral nifedipine had lowered blood pressure more quickly than that of intravenous labetalol during hypertensive emergency in pregnancy which was different from our present study.

Lakshmi et al (2012) ${ }^{\mathbf{1 5}}$ stated that the magnitude of fall in Systolic BP, Diastolic BP and Mean Arterial Pressure was greater in the labetalol group compared to the nifedipine group $(\mathrm{P}<0.05)$. Target $\mathrm{BP}$ was achieved in $90 \%$ in the nifedipine group and $92 \%$ in the labetalol group. Maternal and foetal adverse effects were infrequent. Thereby concluding both oral nifedipine and intravenous labetalol were effective in the treatment of hypertensive crisis. Yet intravenous labetalol may have benefits because it is more effective in reducing the Systolic BP, Diastolic BP and Mean Arterial Pressure to target levels with a lower number of doses. As per our present study, both intravenous labetalol and oral nifedipine are almost equally efficacious with minimal side effects in case of both the drugs.

Scando JA (1999) ${ }^{16}$ conducted a double-blind trial with the purpose to compare the haemodynamic effects of orally administered nifedipine and intravenously administered labetalol in pre-eclamptic hypertensive emergencies. Their result showed that nifedipine group had a cardiac index of $3.08 \pm 0.51 \mathrm{~L} / \mathrm{min}$. per square metre. There was a $43 \%$ increase in the cardiac index after nifedipine administration $(p=0.0008)$. There was no significant effect in the labetalol 
group ( $p=0.697)$. There was a significant decrease in the systemic vascular resistance index after nifedipine administration $(\mathrm{p}=0.002)$ but no significant effect on this index after labetalol use $(\mathrm{p}=0.479)$. The mean arterial pressure was significantly affected in both groups as follows: nifedipine, $\mathrm{p}=0.001$, labetalol, $\mathrm{p}=0.004$. An insignificant increase in heart rate with nifedipine $(p=0.147)$ and a significant decrease with labetalol $(\mathrm{p}=0.034)$ were noted. These parameters were not studied in our study but when the adverse effects were studied it showed that patients receiving oral nifedipine had postural hypotension in $4 \%$ cases and drowsiness $4 \%$ cases.

As per NICE clinical guideline 107 - Hypertension in pregnancy, 7 the first-line antihypertensives which can be used in severe pregnancy-induced hypertension are labetalol (oral/intravenous), hydralazine (intravenous) or nifedipine (oral). Of these we had chosen intravenous labetalol and oral nifedipine for controlling the Blood Pressure in severe preeclampsia. The blood pressure targeted in our study was $150 / 90 \mathrm{~mm}$ of $\mathrm{Hg}$ which is also in keeping with the recommendation given in the Cochrane Review prepared and maintained by The Cochrane Collaboration and published in The Cochrane Library 2013, Issue 7.13

\section{Limitation of the Study}

It is a randomised control study but not double blind, so there is a chance of observer bias. Sample size was also calculated by convenience. Adverse effects of the drugs not objectively measured. Patients in both the groups were age \& parity matched with similar range of SBP \& DBP but whether there was already any end organ \& systemic involvement, was not studied properly. Longterm outcome was not observed.

\section{CONCLUSION}

According to the results obtained, we can well conclude that both the labetalol and nifedipine regimens are almost equally effective and well tolerated. Labetalol seems to be safer, with quicker control of blood pressure with fewer side effects. The outcome of pregnancy appears to be favourable with labetalol in hypertensive disorders of pregnancy. Yet nifedipine may be chosen because it is less cumbersome with oral administration, flat dose schedule and better patient compliance. Considering the limitations of our study, larger multi-centric randomised double-blind study is necessary for definite conclusion.

\section{REFERENCES}

[1] American College of Obstetricians and Gynecologists. Diagnosis and management of preeclampsia and eclampsia. ACOG Practice Bulletin No. 33. Obstet Gynecol 2002;99:159-67.

[2] Sibai BM. Preeclampsia-Eclampsia. Curr Prob Obstet Gynecol \& Fertil 1990;13:1-45.
[3] Sibai BM. Chronic hypertension during pregnancy. In: Sciarra J. edr. Gynecology and Obstetrics. Philadelphia: JB Lippincott 1989:1-8.

[4] Cunningham FG, Leveno KJ, Bloom SL, et al. Pregnancy hypertension. Text book of Williams Obstetrics. 23rd edn. New York: McGraw-Hill 2010:706-57.

[5] Walfisch A, Hallack M. Hypertension. In: James DK. High risk pregnancy. $3^{\text {rd }}$ edn. Philadelphia: Elseiver 2006:772-97.

[6] Raheem IA, Saaid R, Omar SZ, et al. Oral nifedipine versus intravenous labetalol for acute blood pressure control in hypertensive emergencies of pregnancy: a randomised trial. Br J Obstet Gynecol 2012;119(1):7885.

[7] National Institute of Health and Clinical Excellence. Hypertension in pregnancy. The management of hypertensive disorders during pregnancy. Clinical guidelines CG107 Issued: August 2010. http://guidance.nice.org.uk/CG107.

[8] Waisman GD, Mayorga LM, Cámera MI, et al. Magnesium plus nifedipine: potentiation of hypotensive effect in preeclampsia? Am J Obstet Gynecol 1988;159(2):308-9.

[9] Michael CA. The evaluation of labetalol in the treatment of hypertension complicating pregnancy. $\mathrm{Br}$ J Clin Pharmacol 1982;13(Suppl 1):127S-31S.

[10] Mabie WC, Gonzalez AR, Sibai BM, et al. A comparative trial of labetalol and hydralazine in the acute management of severe hypertension complicating pregnancy. Obstet Gynecol 1987;70(3 Pt 1):328-33.

[11] Magee LA, Elran E, Bull SB, et al. Risks and benefits of beta-receptor blockers for pregnancy hypertension: overview of the randomized trials. Eur J Obstet Gynecol Reprod Biol 2000;88(1):15-26.

[12] Vermillion ST, Scardo JA, Newman RB, et al. A randomized, double blind trial of oral nifedipine and intravenous labetalol in hypertensive emergencies of pregnancy. Am J Obstet Gynecol 1999;181(4):858-61.

[13] Duley L, Meher S, Jones L. Drugs for treatment of very high blood pressure during pregnancy. The Cochrane Syst Rev 2013;(7):CD001449.

[14] Shekhar S, Sharma C, Thakur S, et al. Oral nifedipine or Intravenous labetalol for hypertensive emergency in pregnancy: a randomised controlled trial. Obstet Gynecol 2013;122(5):1057-63.

[15] Lakshmi BS, Dasari P. Oral nifedipine versus intravenous labetalol in hypertensive urgencies and emergencies of pregnancy: a randomised controlled trial. Obstetric Medicine 2012;5(4):171-5.

[16] Scardo JA, Vermillion ST, Newman RB, et al. A randomized, double blind, hemodynamic evaluation of nifedipine and labetalol in pre-eclamptic hypertensive emergencies. Am J Obstet Gynecol 1999;181(4):862-6. 